九州大学学術情報リポジトリ

Kyushu University Institutional Repository

\title{
Biodegradation of Daunomycin Post-Production Wastes by Bjerkandera Adusta R59
}

Cho, Nam-Seok

Wood and Paper Science, Chungbuk National University

Kornillowiczcarz, Kowalska

Department of Microbiology, Agricultural Academy

Ginalska, Grazyna

Department of Biochemistry, Maria Curie-Sklodowska University

Cho, Hee-Yeon

Molecular Microbiology and Immunology, University of Southern California

他

https://doi.org/10.5109/16104

出版情報: 九州大学大学院農学研究院紀要. 54 (2)，pp.279-284，2009-10-29. Faculty of Agriculture, Kyushu University

バージョン :

権利関係 : 


\title{
Biodegradation of Daunomycin Post-Production Wastes by Bjerkandera Adusta R59
}

\section{Nam-Seok CHO ${ }^{1}$, Kowalska KORNILLOWICZCARZ ${ }^{2}$, Grazyna GINALSKA ${ }^{3}$, Hee-Yeon $\mathrm{CHO}^{4}$, Soo-Jeong SHIN ${ }^{1}$ and Shoji OHGA*}

\author{
Laboratory of Forest Resources Management, Division of Forest Ecosphere Management, \\ Department of Forest and Forest Products Sciences, Kyushu University, \\ Sasaguri, Fukuoka 811-2415, Japan \\ (Received May 18, 2009 and accepted July 13, 2009)
}

\begin{abstract}
Wastes from industrial production of daunomycin belong to strongly toxic and recalcitrant substances. This study was investigated to the potential use of Bjerkandera adusta R59 as inoculum in process of daunomycin degradation in soil. Possible interactions between R59 strain and soil microorganisms during decay of wastes containing this toxic compound were also tested. Process of degradation of daunomycin post-production wastes in soil was described. Experiments were conducted in model systems. Degradation process proceeded the most efficiently in soil samples inoculated with Bjerkandera adusta R59 fungal strain, capable of decolorization of that cytostatic xenobiotic. Decrease of the waste biomass, carbon and daunomycin concentration (in daunomycin-rich pulp) as well as phenolics level (in post-production effluent) proved the effectiveness of this process, which was shown to depend on peroxidase biosynthesis in soil by $B$. adusta or other soil strains. Activity of this enzyme was the highest in version of experiment containing Bjerkandera adusta R59 fungal strain.
\end{abstract}

\section{INTRODUCTION}

Wastes after industrial production of anticancer anthracyclic antibiotics (daunomycin, adriamycin) belong to strongly toxic and recalcitrant substances. Anthracyclins are produced by Actinomycetales, including Streptomyces peucetius synthesizing daunomycin (Grein, 1987). Daunomycin is a glicoside composed of aminosugar, three anthracyclic rings (anthraquinonic compound) and metoxylic groups attached to first ring (Grein, 1987; Strauss, 1987). Anthraquinonic compound of daunomycin plays a role of chromophoric group - crucial in biological activity of this antibiotic. Cytostatic action of daunomycin is based on the drug-DNA linking during intercalation (Grein, 1987; Strauss, 1987). This antibiotic and products of its conversion possesses a wide anticancer spectrum, in particular in treatment of leukaemia (Strauss, 1987). Wastes from industrial production of daunomycin, after chemical inactivation by sodium subchlorate method, are directed to drain refineries. This leads to extreme chlorides concentrations in water reservoirs and to mismanagement of organic material (Streptomyces peucetius mycelium). Methods of microbial bioremediation of these wastes are commonly considered as less harmful for natural environment than chemical utilization.

Abilities for degradation of anthraquinones deriva-

\footnotetext{
${ }^{1}$ Wood and Paper Science, Chungbuk National University, Cheongju 361-763, Korea

${ }^{2}$ Department of Microbiology, Agricultural Academy, 20-069 Lublin, Poland

${ }^{3}$ Department of Biochemistry, Maria Curie-Sklodowska University, 20-031 Lublin, Poland

${ }^{4}$ Molecular Microbiology and Immunology, University of Southern California, Los Angeles, CA 90089, USA

* Corresponding author (E-mail: ohga@forest.kyushu-u.ac.jp)
}

tives were proved for several bacterial strains e.g. Bacillus subtilis, Pseudomonas spp., Alcaligenes spp. (Bokhamy et al., 1994; Itoh et al., 1993; Nigam et al., 1996), yeasts e.g. Pichia anomala (Itoh et al., 1996) and fungi, including Aspergillus terreus, A. niger, Geotrichum candidum (Fujii et al., 1988; Fujitake et al., 1998; Kim et al., 1995). Special abilities in this field are presented by ligninolytic fungi representing basidiomycete, so called white-rot fungi: Phanerochaete chrysosporium, Trametes (Coriolus) versicolor, Pleurotus cinnabarinus, Irpex lacteus (De Jong et al., 1992; Glenn and Gold, 1983; Itoh et al., 1998; Jones et al., 1993; Kottermann et al., 1994; Nigam et al., 1996). Ligninolytic enzymes synthesized by these fungi - laccase and peroxidases - decay the mentioned xenobiotics on oxidative pathway (Jones et al., 1993; Novotny et al., 2000; Vyas et al., 1994).

Among already known microorganisms capable of biodegradation of anthraquinonic derivatives there are no strains which could decolorize and degrade the anthracyclic antibiotics. It is therefore worth noting that we have isolated a new ligninolytic fungal strain, initially classified as Geotrichum-like for its morphological similarity to this strain (Ginalska et al., 2004; Malarczyk et al., 1998). This fungus was characterized by decolorization and degradation potential against daunomycin in in vitro cultures, mainly due to peroxidase biosynthesis. Genetical analysis of this fungus revealed that it is an anamorphic stadium (Geotrichum-like) of Bjerkandera adusta (Basidiomycota) strain, representing white-rot fungi.

This research presents a detailed investigation into the potential use of Bjerkandera adusta R59 as inoculum in process of daunomycin degradation in soil. Possible interactions between R59 strain and soil microorganisms during decay of wastes containing this toxic 
compound were also tested.

\section{MATERIALS AND METHODS}

\section{Daunomycin source}

Wastes after pharmaceutical industrial production of daunomycin were used in our research. They were: the pulp (mycelium of Streptomyces peucetius, synthesizing the antibiotic) and effluent (culture liquid after daunomycin extraction). The wastes were kindly provided by Biotechnology and Antibiotics Institute (Warsaw, Poland). Table 1 presents some of chemical features of these materials.

\section{Fungal strain}

Samples of black earth soil (Phaeosols from a field near Lublin (South-Eastern Poland) were used for fungus isolation. The samples contained (in \%): humus 3.95, $\mathrm{N}_{\text {tot. }}$ 0.210; $\mathrm{pH}_{\mathrm{KCl}}$ 7.45. Fungi were isolated using a trapping method. The pulp after industrial production of daunomycin (Streptomyces peucetius mycelium) was used as trapping material. Detailed description of fungus isolation was given elsewhere (Ginalska et al., 2004). Finally, on a base of morphological and genetic features, R59 strain was identified as an anamorphic stadium (Geotrichum-like) of Bjerkandera adusta (Willd. Ex. Fr.) P. Karst, representing white-rot fungi. Identification of nucleotide sequences (rRNA gene fragment) of the fungus are available in Gene Bank under a number AY 319191. The strain was also deposited in CCBAS culture collection under accession number CCBAS930.

\section{Soil}

The soil for our experiments contained only small quantities of organic substances and mineral colloids, in order to limit the sorption of daunomycin. The soil was classified as podzolic soil (Haplic Podzols, acc. FAO) developed from sand. Characteristics of basal chemical and physical features of this soil are summarized in
Table 2.

\section{Model of experiment}

Fresh soil from cultivation field from the upper (up to $20 \mathrm{~cm}$ ) layer. It was passed through a sieve (mesh: $0.2 \mathrm{~cm}$ ), humidified to $60 \%$ of its total water capacity and placed into $1000 \mathrm{~cm}^{3}$ vessels (1 kg of soil per one vessel; height of $15 \mathrm{~cm}$ ). Daunomycin-rich material was put into the vessels in two experimental versions: with postproduction pulp (I) and post-production effluent (II).

Version I: $15 \mathrm{~g}$ portions of daunomycin-rich pulp (20\% of dry weight) in poliamide-6 bags (see 2.1) were put into the soil in vessels ( $5 \mathrm{~cm}$ under soil surface) in following combinations:

1 - without any additives (control)

2 - with $1 \mathrm{~cm}^{3}$ of homogenized Bjerkandera adusta $\mathrm{R} 59$ mycelium ( $10^{6}$ c.f.u.)

3 - with $1 \mathrm{~cm}^{3}$ of homogenized Bjerkandera adusta R59 mycelium (10 6 c.f.u.) and 1\% glucose

Version II: daunomycin-rich post-production effluent was used in following combinations:

1 - soil without additives (control 1 )

2 - soil with $50 \%$ daunomycin effluent $\left(50 \mathrm{~cm}^{3}\right)$

3 - soil with $15 \mathrm{~cm}^{3}$ of homogenized Bjerkandera adusta R59 mycelium (10 ${ }^{6}$ c.f.u.) (control 2)

4 - soil with $50 \%$ daunomycin effluent $\left(50 \mathrm{~cm}^{3}\right)$ and $15 \mathrm{~cm}^{3}$ of homogenized Bjerkandera adusta R59 mycelium ( $10^{6}$ c.f.u.)

Extraction of phenolic compounds was performed according to Hruszka (1982): $15 \mathrm{~g}$ of dry soil material was extracted twice with $50 \mathrm{~cm}^{3}$ of mixture containing: $\mathrm{C}_{2} \mathrm{H}_{5} \mathrm{OH}$ :redistilled water: $\mathrm{CH}_{3} \mathrm{COOH}(70: 28: 2)$ for $8 \mathrm{~h}$. The filtrate was dried and residues were dissolved in $25 \mathrm{~cm}^{3}$ of redistilled water. Both versions in each combinations were prepared in duplicates. Vessels were incubated for 5 months at $20^{\circ} \mathrm{C}\left( \pm 2{ }^{\circ} \mathrm{C}\right)$ in conditions of controlled humidity. Chemical and biochemical assays were performed after 3, 30, 60, 90, 120 and 150 days of exper-

Table 1. Chemical composition of daunomycin wastes (g. $\mathrm{kg}^{-1}$ of dry weight)

\begin{tabular}{|c|c|c|c|c|c|c|}
\hline Waste & $\begin{array}{c}\text { Dry } \\
\text { weight }\end{array}$ & $\begin{array}{c}\text { Daunomycin } \\
\text { Content }\end{array}$ & Carbon & Hydrogen & Nitrogen & $\mathrm{pH}$ \\
\hline $\begin{array}{l}\text { Daunomycin } \\
\text { pulp }\end{array}$ & 200 & $5 \cdot 10^{-4}$ & 408.9 & 57.5 & 51.7 & 5.8 \\
\hline $\begin{array}{l}\text { Daunomycin } \\
\text { effluent }\end{array}$ & 30 & $2.67 \cdot 10^{-3}$ & 295.3 & 39.2 & 11.9 & 3.5 \\
\hline
\end{tabular}

Table 2. Some physical and chemical features of soil (g. $\mathrm{kg}^{-1}$ of dry weight)

\begin{tabular}{ccccccccc}
\hline N tot. & C org. & Humus & $\mathrm{Mg}$ & $\mathrm{CaCO}_{3}$ & $\mathrm{P}_{2} \mathrm{O}_{5}$ & $\mathrm{~K}_{2} \mathrm{O}$ & $\mathrm{pH}_{\mathrm{KCl}}$ \\
\hline 0.55 & 6.1 & 10.5 & 0.038 & 3.4 & 0.325 & 0.119 & 5.92 \\
\hline \multicolumn{7}{c}{ Particle size distribution (diameters in mm) } \\
\hline $1.0-0.5$ & $0.5-0.25$ & $0.25-0.1$ & $0.1-0.05$ & $0.05-0.02$ & $0.02-0.006$ & $0.006-0.002$ & $<0.002$ \\
\hline 8 & 30 & 28 & 10 & 14 & 7 & 2 \\
\hline
\end{tabular}


iment.

\section{Analytical procedures}

Periodical assays of daunomycin-rich pulp (for version I) introduced into soil included the estimations of:

- decrease of dry biomass (after complete drying at $105^{\circ} \mathrm{C}$ )

- daunomycin content $\left(\mathrm{A}_{480} \mathrm{~nm}\right)$ after extraction of $100 \mathrm{mg}$ of dry biomass of daunomycin pulp with $10 \mathrm{~cm}^{3}$ of ethanol. Amount of the antibiotic was calculated using standard curve for pure daunomycin (ICN)

- carbon content in dry biomass of pulp (using Perkin Elmer CHN 2400)

Assays of daunomycin-rich effluent (for version II) included estimation of:

- phenolics level $\left(\mathrm{A}_{725} \mathrm{~nm}\right)$ according to Swain and Hillis (1959).

- peroxidase activity: $10 \mathrm{~g}$ samples of soil were dizintegrated with alumina and $5 \mathrm{~cm}^{3}$ of Tris/HCl buffer pH 7.5, centrifuged at $3000 \mathrm{rpm}$. Activity of enzyme was estimated in supernatant according to Maehly and Chance method with o-dianisidine as a substrate (Maehly and Chance, 1954).

In both experiment the viability of Bjerkandera adusta R59 was tested by material layout method (for version I) or by dilution plating method (for version II) on selective medium for fungi (Martin, 1950). Identification of B. adusta R59 strain was performed on a base of microscopic observations (Geotrichum-type sporulation) and confirmed by decolorization of daunomycin on Petri dishes containing agarized medium. All assays were performed in triplicates (except of estimation of carbon content - in duplicates). Results were analyzed by the statistical method of variance analysis with Tukeya confidence intervals defined in our work as LSD (lowest significant difference) and by correlation method.

\section{RESULTS AND DISCUSSION}

\section{Investigations of biodegradation of daunomycin- rich post-production pulp}

Biomass of the pulp and its carbon content decreased regularly for the whole time of experiment duration. Decreases of biomass of pulp were considerably high only up to third month of the test - during this period the biomass of pulp reached 53.2\% of its initial weight. Drop of carbon content was the most significant during first month of investigation - afterwards it was not so noticeable (Table 3 and Table 4). Considering a decrease of biomass and carbon content as criteria for estimation of pulp decay it was found that biodegradation was performed with the lowest rate in control soil samples (without B. adusta R59). The presence of this fungus in soil induced an increasing drop of biomass and carbon content, in comparison with control samples (Table 3 and Table 4). Specially visible decrease of pulp biomass was observed in comparison with the combination with the sole fungal inoculum (after 5 months of experiment).

Results obtained in described experiment revealed
Table 3. Average values of pulp biomass (in \% of its initial weight)

\begin{tabular}{crcc}
\hline \multirow{2}{*}{ Time (days) } & \multicolumn{3}{c}{ Version of experiment * } \\
\cline { 2 - 4 } & 1 & 2 & 3 \\
\hline 0 & 100.0 & 100.0 & 100.0 \\
30 & 83.3 & 79.5 & 76.5 \\
60 & 67.4 & 63.6 & 64.4 \\
90 & 60.0 & 57.3 & 57.7 \\
120 & 57.2 & 52.4 & 50.0 \\
150 & 56.5 & 46.8 & 45.8 \\
\hline
\end{tabular}

* Explanations: 1 - daunomycin pulp in soil (control); 2 daunomycin pulp in soil with $B$. adusta R59; 3 - daunomycin pulp in soil with $B$. adusta $\mathrm{R} 59$ and $1 \%$ of glucose; $\mathrm{LSD}_{0.05}$ for time $=4.7 ; \mathrm{LSD}_{005}$ for version of experimen $=2.4$

Table 4. Average values of carbon content in pulp (in \% of its initial content)

\begin{tabular}{cccc}
\hline \multirow{2}{*}{ Time (days) } & \multicolumn{3}{c}{ Version of experiment } \\
\cline { 2 - 4 } & 1 & 2 & 3 \\
\hline 0 & 100.0 & 100.0 & 100.0 \\
30 & 96.2 & 91.5 & 92.8 \\
60 & 92.9 & 84.2 & 88.3 \\
90 & 88.7 & 82.9 & 84.2 \\
120 & 86.5 & 79.7 & 80.4 \\
150 & 88.5 & 78.6 & 79.1 \\
\hline
\end{tabular}

Explanations: 1 - daunomycin pulp in soil (control); 2 - daunomycin pulp in soil with $B$. adusta R59; 3 - daunomycin pulp in soil with $B$. adusta $\mathrm{R} 59$ and $1 \%$ of glucose; $\mathrm{LSD}_{0.05}$ for time=5.7; $\mathrm{LSD}_{0.05}$ for version of experiment=2.4

that highly toxic daunomycin post-production wastes (pulp $-S$. peucetius mycelium and effluent) undergo a slow biodegradation when introduced into soil. Inoculating the soil samples with Bjerkandera adusta R59 strain, capable of effective decolorization of this antibiotic, increased the rate of daunomycin degradation in both pulp and effluent after industrial production of this substance. It was confirmed by higher decrease of biomass, carbon and daunomycin content (pulp decay) and phenolics level (effluent degradation) in comparison with samples without the fungus. Process of biodegradation of these wastes was substantially correlated with time of their contact with soil. After 3 month of experiment, biomass of waste and daunomycin content in presence of R59 decreased to $50 \%$ and $40 \%$ of their initial values, respectively. In analogical combination with daunomycin effluent, phenolics level dropped to $20 \%$ of its initial concentration.

The results show that pulp biomass degradation was accompanied by a decrease of daunomycin content. Significant decrease of daunomycin concentration in control combination was observed only during first month of contact with soil. In other combinations, drop of antibi- 
otic content was fast and intensive. Final amount of daunomycin was the lowest in version I containing both R59 strain and glucose. The influence of the sugar presence was the most visible between $30^{\text {th }}$ and $60^{\text {th }}$ day of experiment (Table 5). Statistical estimations showed that changes in pulp biomass, carbon and daunomycin content were strongly correlated with the time of experiment (Table 6). It is possible that some daunomycin from the pulp introduced into soil could be removed from the system in non-enzymatic way - eluted with water - for its solubility in this liquid (Grein, 1987). Significant drop of daunomycin content during the first month of experiment in sample non treated with R59 seems to confirm this hypothesis.

Table 5. Average values of daunomycin content in pulp (in \% of its initial content)

\begin{tabular}{crrr}
\hline \multirow{2}{*}{ Time (days) } & \multicolumn{3}{c}{ Version of experiment } \\
\cline { 2 - 4 } & \multicolumn{1}{c}{1} & \multicolumn{1}{c}{2} & \multicolumn{1}{c}{3} \\
\hline 0 & 100.0 & 100.0 & 100.0 \\
3 & 92.8 & 83.8 & 81.7 \\
30 & 65.9 & 68.0 & 52.7 \\
60 & 63.4 & 49.9 & 37.3 \\
90 & 57.9 & 36.9 & 30.5 \\
120 & 52.6 & 32.4 & 28.3 \\
150 & 51.2 & 32.9 & 28.6 \\
\hline
\end{tabular}

Explanations: 1 - daunomycin pulp in soil (control); 2 - daunomycin pulp in soil with $B$. adusta R59; 3 - daunomycin pulp in soil with $B$. adusta $\mathrm{R} 59$ and $1 \%$ of glucose $\mathrm{LSD}_{0.05}$ for time=3.5; $\mathrm{LSD}_{0.05}$ for version of experiment $=1.8$

Table 6. Correlation coefficients $(r)$ and significance levels $(\alpha)$ between the duration of experiment and pulp weight, daunomycin content or carbon content for particular versions of experiment

\begin{tabular}{|c|c|c|c|c|c|c|}
\hline \multirow{2}{*}{$\begin{array}{c}\text { Experiment } \\
\text { version }\end{array}$} & \multicolumn{2}{|c|}{ Pulp weight } & \multicolumn{2}{|c|}{$\begin{array}{c}\text { Daunomycin } \\
\text { content }\end{array}$} & \multicolumn{2}{|c|}{ Carbon content } \\
\hline & $r$ & $A$ & $r$ & $\alpha$ & $r$ & $\alpha$ \\
\hline 1 & -0.8464 & 0.05 & -0.8916 & 0.01 & -0.9204 & 0.01 \\
\hline 2 & -0.8803 & 0.01 & -0.9320 & 0.01 & -0.8300 & 0.05 \\
\hline 3 & -0.9056 & 0.01 & -0.8732 & 0.05 & -0.9486 & 0.01 \\
\hline
\end{tabular}

Explanations: 1 - daunomycin pulp in soil (control); 2 - daunomycin pulp in soil with $B$. adusta R59; 3 - daunomycin pulp in soil with $B$. adusta R59 and 1\% of glucose.

\section{Biodegradation of daunomycin-rich post-produc- tion effluent}

Results obtained previously showed that B. adusta R59 strain plays a significant role in biodegradation of daunomycin in soil milieu. Assuming the drop of phenolic compounds as a indicator of daunomycin decay its was found that phenolics level in control soil without R59 (control I) remained practically unchanged during experiment time. In soil samples inoculated with fungus but without daunomycin effluent (control II) a slight drop of these substances was found only between $30^{\text {th }}$ and $60^{\text {th }}$ day of experiment. In both combinations enriched with daunomycin effluent decreased intensively until $90^{\text {th }}$ day of test; then it remained stable (Table 7). It was estimated that at the end of experiment phenolics content in samples only with daunomycin dropped to 35\% of its initial value, while in samples with daunomycin and inoculated with B. adusta R59 - to 20\%. Changes in peroxidase activity level showed generally the presence of two maxima in first an third month of experiment (except of in control 1) (Table 8).

The smallest variability in peroxidase activity appeared in soil samples without any additives. The highest variability and higher value of the enzyme activity was measured for soil containing R59 without antibiotic, while the highest peroxidase activity occurred in combination with both R59 and daunomycin in soil (Table 8). Similarly as in previous experiment, analysis of correlation revealed that only phenolics level correlates with time in significant extent. There was no correlation between time of experiment and peroxidase activity (Table 9).

Autochthonic microorganisms colonizing soil used in our experiment synthesized small amounts of peroxidase. However, the presence of daunomycin-rich effluent in the soil systems brought about a significant increase

Table 7. Average values of phenolics content (in mg $\mathrm{kg}^{-1}$ of soil dry weight)

\begin{tabular}{ccccc}
\hline \multirow{2}{*}{ Time (days) } & \multicolumn{4}{c}{ Version of experiment } \\
\cline { 2 - 5 } 3 & 1 & 2 & 3 & 4 \\
\hline 30 & 0.901 & 1.439 & 0.911 & 1.412 \\
60 & 0.880 & 1.407 & 0.882 & 0.860 \\
90 & 0.880 & 1.090 & 0.730 & 0.523 \\
120 & 0.784 & 0.509 & 0.605 & 0.264 \\
150 & 0.880 & 0.510 & 0.600 & 0.266 \\
\hline
\end{tabular}

Explanations: 1 - soil (control 1); 2 - soil with daunomycin effluent; 3 - soil inoculated with B. adusta R59 (control 2); 4 - soil with daunomycin effluent and inoculated with $B$. adusta R59; $\mathrm{LSD}_{0.05}$ for time $=0.042 ; \mathrm{LSD}_{0.05}$ for version of experiment $=0.031$

Table 8. Average values of peroxidase activity (in $\mathrm{U} \cdot 10^{-1} \cdot \mathrm{kg}^{-1}$ of soil dry weight)

\begin{tabular}{crrrr}
\hline \multirow{2}{*}{ Time (days) } & \multicolumn{4}{c}{ Version of experiment } \\
\cline { 2 - 5 } & \multicolumn{1}{c}{1} & 2 & \multicolumn{1}{c}{3} & \multicolumn{1}{c}{4} \\
\hline 3 & 0.000 & 0.000 & 0.000 & 0.000 \\
30 & 10.000 & 19.463 & 17.700 & 36.320 \\
60 & 7.380 & 19.543 & 16.951 & 23.910 \\
90 & 6.622 & 33.789 & 20.475 & 31.350 \\
120 & 5.768 & 14.481 & 3.758 & 14.481 \\
150 & 0.000 & 12.812 & 0.000 & 11.369 \\
\hline
\end{tabular}

Explanations: 1 - soil (control 1); 2 - soil with daunomycin effluent; 3 - soil inoculated with B. adusta R59 (control 2); 4 - soil with daunomycin effluent and inoculated with $B$. adusta R59; $\mathrm{LSD}_{0.05}$ for time=3.425; $\mathrm{LSD}_{0.05}$ for version of experiment=2.507 
Table 9. Correlation coefficients $(r)$ and significance levels $(\alpha)$ between the incubation time and phenolics level or peroxidase activity for particular versions of experiment

\begin{tabular}{cccccc}
\hline \multirow{2}{*}{$\begin{array}{c}\text { Version of } \\
\text { experiment }\end{array}$} & \multicolumn{2}{c}{ Phenolics level } & & \multicolumn{2}{c}{ Peroxidase activity } \\
\cline { 2 - 3 } \cline { 5 - 6 } \cline { 5 - 6 } & $R$ & $\alpha$ & & $R$ & $\alpha$ \\
\hline 2 & -0.1843 & no & & -0.1922 & - \\
3 & -0.9275 & 0.01 & & 0.2954 & - \\
4 & -0.9316 & 0.01 & & -0.2285 & - \\
\hline
\end{tabular}

Explanations: 1 - soil (control 1); 2 - soil with daunomycin effluent; 3 - soil inoculated with B. adusta R59 (control 2); 4 - soil with daunomycin effluent and inoculated with B. adusta R59; "no" - no significance of the correlation coefficient; " - " impossible to estimate

of peroxidase activity, specially in combinations containing $B$. adusta mycelium. This phenomenon proves the crucial role of this enzyme in biodegradation of tested xenobiotic. These results are confirmed by research performed by other authors (De Jong et al., 1992; Field et al., 1995; Heinfling et al., 1998a; Heinfling et al., 1998b; Kottermann et al., 1994), stating that peroxidases synthesized by Bjerkandera sp. including B. adusta are effective in process of degradation of aromatic xenobiotics, including anthraquinonic dyes Poly R-478 containing methoxyl groups and therefore structurally closely related to daunomycin.

Increase of peroxidase activity in soil containing daunomycin was accompanied by drop of phenolic compounds level, specially after inoculation with B. adusta strain. This effect confirms the contribution of fungal peroxidases in biodegradation of aromatic compound of daunomycin and phenolics transformation in the system applied in described experiments. Interestingly, the phenolics level dropped also in combination of soil with fungus but without daunomycin; the peroxidase activity in this system was also higher in comparison with pure soil without any additives. Probably B. adusta shows the degradation abilities also against natural phenolic compound present in soil, showing the high possible adaptation abilities of this fungus. Therefore, B. adusta possesses a high value for its potential in biotechnological applications. Rate of daunomycin removal from post-production pulp inoculated with $B$. adusta R59 increased significantly in presence of glucose. Similar observations were reported by Martens and Zadrazil (Martens and Zadrazil, 1996; Martens and Zadrazil, 1998). Glucose was also a main energy source in experiment on decolorizing of anthraquinonic dyes by Bjerkandera sp. BOS55 strain (Kottermann et al., 1994) and Geotrichum candidum Dec1 (Kim et al., 1995; Kim and Shoda, 1999).

Considering the above results, it is highly probable that B. adusta R59 decays daunomycin on cometabolic way rather that during its primary metabolic pathways. It is in agreement with present hypothesis on biodegradation of aromatic compounds by fungi. These processes are performed by fungal enzymes but degradation products are rarely incorporated into fungal material.
For this reasons, aromatic compounds undergo degradation only in presence of other easily assimilated substrates. Addition of glucose stimulated daunomycin degradation but simultaneously decreases the rate of biomass decay and mineralization of organic carbon of post-production pulp. Most probably this effect was a result of catabolic repression of enzymes participating in decay of tested daunomycin wastes. The addition of glucose induced a decrease of waste biomass just after 5 months of its contact with soil therefore when this sugar has been already metabolized. These speculations are supported by numerous reports on glucose repression of fungal enzymes degrading polysaccharides and proteins (Carline and Watkinson, 1994; Kornillowicz-Kowalska, 1997). The results presented in this work show the usefulness of B. adusta R59 strain in remediation of environment polluted by toxic anthracyclins. This strain reveals a long viability in daunomycin-enriched soils which makes it additionally more valuable for biotechnological purposes. Bjerkandera adusta R59 covers 5 $15 \%$ of total fungal population settling the antibioticenriched soil mentioned above.

Our results allows for a hypothesis that autochthonic soil microorganisms participate in biodegradation of tested daunomycin wastes. The daunomycin pulp content decreased to $58 \%$ after 3 months of culturing in soil sample without B. adusta inoculation; a significant drop of phenolics level (to $65 \%$ of its initial content) and an increase of peroxidase activity was observed in analogical combination but with daunomycin effluent. These observations suggest that self-selection of a team of microorganisms capable of daunomycin biotransformation took place. Streptomyces peucetius mycelium, left after industrial daunomycin production, contained not only this toxic antibiotic but also a significant amount of nitrogen (Table 1). According to our results, the cooperation of $B$. adusta action (daunomycin decay) and autochthonic soil microorganisms activity (the degradation of remaining biomass of $S$. peucetius mycelium) could be useful in composting method decay of recalcitrant compounds (e.i. ligninocellulose).

\section{REFERENCES}

Bokhamy M., N. Adler, C. Pulgarin, M. Deront, C. Seignez and P. Péringer 1994 Degradation of sodium anthraquinone sulphonate by free and immobilized bacterial cultures. Appl. Microbiol. Biotechnol., 41: 110-116

Carline J. M. and S. C. Watkinson 1994 The Fungi. Academic Press. London. pp. 165-267

De Jong E., J. A. Field, J. A. M. de Bont 1992 Evidence for a new extracellular peroxidase. Manganese-inhibited peroxidase from the white-rot fungus, Bjerkandera sp. BOS55. Federat Euro Biochem. Soc., 299: 107-110

Field J. A., F. Boelsma, H. Baten and W. H. Rulkens 1995 Oxidation of anthracene in water/solvent mixtures by the white-rot fungus. Bjerkandera sp. strain BOS55. Appl. Microbiol. Biotechnol., 44: 234-240

Fujii I., Y. Ebizuka and U. Sankawa 1988 A novel anthraquinone ring cleavage enzyme from Aspergillus terreus. J. Biochem., 103: $878-883$

Fujitake N., T. Suzuki, M. Fukumoto and Y. Oji 1998 Predomination of dimers over naturally occurring anthraqui- 
nones in soil. J. Nat. Prod., 61: 189-192

Glenn J. K. and M. H. Gold 1983 Decolorization of several polymeric dyes by the lignin-degrading basidiomycete Phanerochaete chrysosporium. Appl. Environ. Microbiol., 45: $1741-1747$

Ginalska G., R. Bancerz and T. Korniłłowicz-Kowalska 2004 A thermostable lipase produced by a new isolate of Geotrichumlike R59. J. Industrial Microbiol. and Biotechnol., 31(4): $177-182$

Grein A. 1987 Antitumor anthracyclines produced by Streptomyces peucetius. Adv. Appl. Microbiol. 32: 203-215

Heinfling A., M. J. Martinez, A. T. Martinez, M. Bergbauer and U. Szewzyk 1998 Transformation of industrial dyes by manganese peroxidases from Bjerkandera adusta and Pleurotus eryngii in a manganese-independent reaction. Appl. Environ. Microbiol., 64: 2788-2793

Heinfling A., M. J. Martinez, A. T. Martinez, M. Bergbauer and U. Szewzyk 1998 Purification and characterization of peroxidases from the dye-decolorizing fungus Bjerkandera adusta. FEMS Microbiol. Lett., 165: 43-50

Hruszka M. 1982 Investigations into phenolic compounds toxicity in agricultural monocultures. Acta Univ. Agricult. Brno., 30: 79-85

Itoh K., C. Yatome and T. Ogawa 1993 Biodegradation of anthraquinone dyes by Bacillus subtilis. Bull. Environ. Contam. Toxicol., 50: 522-527

Itoh K., Y. Kitade and C. Yatome 1996 A pathway for biodegradationof an anthraquinone dye, C. I. Disperse Red 15, by a yeast strain Pichia anomala. Bull. Environ. Contam. Toxicol., 56: $413-418$

Itoh K., Y. Kitade and C. Yatome 1998 Oxidative biodegradation of an anthraquinone dye Pigment Violet 12, by Coriolus versicolor. Bull. Environ. Contam. Toxicol., 60: 786-790

Jones C. L., G. T. Lonergan and D. E. Mainwaring 1993 The use of digital image segmentation to quantify an aminoanthraquinone dye biotransformation by white-rot fungi. Biotechnol. Techniques, 7: 645-650

Kim S. J., K. Ishikawa, M. Hirai and M. Shoda 1995 Characteristics of a newly isolated fungus Geotrichum candidum Dec 1. which decolorizes various dyes. J. Ferment. Bioeng., 79: 601-607

Kim S. J. and M. Shoda 1999 Decolorization of molasses and a dye by a newly isolated strain of the fungus Geotrichum can- didum Dec1. Biotechnol. Bioeng., 62:114-119

Kornillowicz-Kowalska T. 1997 Studies on the decomposition of keratin waste by saprotrophic microfungi. II. Sulphur and nitrogen balance. Acta Mycol., 32: 81-93

Kottermann M. J. J., E. Heessels, E. de Jong and J. A. Field 1994 The physiology of anthracene biodegradation by the white-rot fungus Bjerkandera sp. strain BOS55. Appl Microbiol Biotechnol., 42: 179-186

Maehly A. C. and B. Chance 1954 The assay of catalases and peroxidases. In: Methods of Biochemical Analysis (ed. Glik D.) Interscience Publish Inc. 1: pp. 357-366

Malarczyk E., T. Kornillowicz and A. Leonowicz 1998 Decolorization of some industrial wastes by soil fungus Geotrichum sp. Proceedings of the 7th International Conference on Biotechnology in "The Pulp and Paper Industry". (M. Paice and J. Saddller eds.) Technical section CPPA, Montreal, Quebec, Canada. vol. C., pp. 219-222

Martens R. and F. Zadrazil 1996 Two-step degradation of pyrene by white-rot fungi and soil microorganisms. Appl. Microbiol. Biotechnol., 46: 653-659

Martens R. and F. Zadrazil 1998 Screening of white-rot fungi for their ability to mineralize polycyclic aromatic hydrocarbons in soil. Folia Microbiol., 43: 97-103

Martin J. P. 1950 Acid rose bengal and streptomycin in the plate method of estimating soil fungi. Soil Science, 19: 215-233

Nigam P., G. McMullan, I. M. Banat and R. Marchant 1996a Decolourisation of effluent from the textile industry by a microbial consortium. Biotechnol. Lett., 18: 117-120

Nigam P., I. M. Banat, D. Singh and R. Marchant 1996b Microbial process for the decolorization of textile effluent containing azo, diazo and reactive dyes. Process Biochemistry, $\mathbf{3 1}$ 435-442

Novotnỳ C., P. Erbanová, T. Cajthaml, N. Rothschild, C. Dosoretz and V. Šašek 2000 Irpex lacteus, a white rot fungus applicable to water and soil bioremediation. Appl. Microbiol. Biotechnol., 54: 850-853

Strauss D. G. 1987 Strukturen der Anthracyclin - Tumoristatica Die Pharmazie (ISSN 0031-7144), 42: 289-303

Swain T. and W. E. Hillis 1959 The phenolic constituents of Prunus domestica. I. J. Sci. Food. Agric., 10: 63-68

Vyas B. R. M., S. Bakowski, V. Sasek and M. Matucha 1994 Degradation of anthracene by selected white rot fungi. FEMS Microbiol. Ecol., 14: 65-70 